\title{
THE IMAGE EVALUATION OF HYPERTROPHIC PNEUMATIC OSTEOARTHROPATHY
}

Claudia Valeria Vierhout (PUC Campinas, Campinas, SP, Brasil), Nadia Regina Bossolan Schincariol (Puc Campinas, Campinas, SP, Brasil), José Alexandre Mendonça (PUC Campinas, Campinas, SP, Brasil), Lucas Eduardo Pedri (PUC Campinas, Campinas, SP, Brasil), André Marun Lyrio (PUC Campinas, Campinas, SP, Brasil), Rubens Bonfiglioli (PUC Campinas, Campinas, SP, Brasil), José Roberto Provenza (PUC Campinas,

Campinas, SP, Brasil), Vanessa Ramos Guissa (PUC Campinas, Campinas, SP, Brasil), Flavia Regina Andrade (PUC Campinas, Campinas, SP, Brasil), Marina de Souza Vieira (PUC Campinas, Campinas, SP, Brasil), Igor Tadeu Garcia Ferreira (PUC Campinas, Campinas, SP, Brasil), Fernanda Bertucci Sanches (PUC Campinas, Campinas, SP, Brasil), Thais Campos Ferreira Pinto (PUC Campinas, Campinas, SP, Brasil)

\section{BACKGROUND}

Hypertrophic pneumatic osteoarthropathy or Bamberger-Pierre-Marie's disease is characterized by nail clubbing and new bone formation in the periosteum, can be primary or secondary to other organs disease, commonly lung lesions, Among the most associated pulmonary conditions are chronic obstructive pulmonary disease, and primary intrathoracic neoplasias. Its etiology is still unclear, some authors associate it to platelet dysfunction and others with increased fibrinolytic activity. It is a cause of joint pain and is a diagnostic hypothesis that should be remembered by rheumatologists.

\section{CASE REPORT}

Man, a smoking pneumopath, with an 80-year old pack, presented in outpatient clinic whit the complaint of mechanical arthralgia in both knees, worse on the right, associated with pain in the peri-articular region of the knees, which began about 4 months ago. At the physical examination, there was anteroposterior enlargement of the thorax, with reduced physiological vesicular murmur, nail clubbing, and no alteration in the physical examinations of the knees. Therefore, the hypothesis of pneumatic hypertrophic osteoarthropathy was made, then a knees magnetic resonance imaging and X-ray of the hands were requested, which, consistents with the diagnostic hypothesis, showed hyperostosis in the studied articulations.

\section{CONCLUSION}

In the image evaluation of hypertrophic pneumatic osteoarthropathy it is common to find hyperostosis, which in association with compatible clinical history and digital clubbing, helps in the diagnosis. In this report, we show very typical images of the condition, hyperostosis in both the hand and knees. 